\title{
PARTICIPAÇÃO INDÍGENA NO COMITÊ DE BACIA HIDROGRÁFICA DO ESTADO DA BAHIA
}

\author{
SANDRA CRISTINA SMITH GALVÃO ${ }^{1}$ \\ UESC/UCSal
}

\begin{abstract}
RESUMO: A crise ambiental da água, com a perda de sua qualidade e má distribuição, é reflexo de uma crise social política e, sobretudo, ética vivida pela comunidade. Para superá-la a sociedade civil organizada e o Estado, através do planejamento participativo, têm criado e implementado políticas públicas de gestão democrática e descentralizada dos recursos hídricos, envolvendo diversos segmentos sociais. A participação indígena tem legalmente recebido papel de destaque neste processo, seja pelo conjunto de valores historicamente cultivados de valorização das águas, seja pelo significado simbólico que possuem os índios, como comunidades que cuidam e preservam a Natureza. Assim, o objetivo da pesquisa foi avaliar a participação indígena na gestão de recursos hídricos, no Estado da Bahia, no período de 2006 a 2009. Para tanto foi mensurado o nível de participação, bem como identificados os fatores que a dificultaram ou facilitaram. Foi utilizada a metodologia da observação participante, com o estudo de caso do Comitê de Bacia Hidrográfica do Rio Itapicuru, com a análise da participação dos povos indígenas Kiriri e Kaimbé, através de uma abordagem sistêmica.
\end{abstract}

PALAVRAS-CHAVE: Participação; Recursos Hídricos; Povos Indígenas; Comitê de Bacia Hidrográfica; Políticas Públicas.

\begin{abstract}
The environmental crisis of water and vital, with the loss of their its quality and poor distribution reflects not only a social and political crisis, but also an ethical one within the community. To overcome this it's important that the organized civil society and the State through participative planning create and implement public democratic policies and decentralize the management of water resources, involving various social segments. The indigenous participation has legally received prominent role in this process either because of the value historically linked to water, or because of the symbolic meaning that the Indians have as communities that care and preserve the nature. The objective of the research was to evaluate indigenous participation in the management of water resources in the state of Bahia, in the period from 2006 to 2009. It was measured the level of participation and identified the factors that hindered or facilitated it. The methodology used was participative observation, case study with the Committee Itapicuru River Basin and an analysis of the participation of Indigenous Peoples Kiriri and Kaimbé through a systemic approach.
\end{abstract}

KEYWORDS: Participation; Water Resources; Indigenous Peoples; Watershed Committee; Public Policy.

\footnotetext{
${ }^{1}$ Mestre em Desenvolvimento Regional e Meio Ambiente pela Universidade Estadual de Santa CruzUESC, Advogada do Município de Lauro de Freitas/BA, Professora da Universidade Católica do Salvador - UCSal. E-mail: ssmithgalvao@ yahoo.com.br .
}

Espaço Ameríndio, Porto Alegre, v. 7, n. 1, p. 146-169, jan./jun. 2013. 
SANDRA C. SMITH GALVÃO - Participação indígena no Comitê de Bacia Hidrográfica...

\section{Introdução}

O artigo tem por objetivo analisar a participação dos povos indígenas na gestão dos recursos hídricos no Estado da Bahia, através de uma abordagem sistêmica, que entende a crise ecológica, social e política atual como reflexo de uma crise de valores.

A escassez, perda da qualidade e má distribuição da água, bem essencial à vida digna, têm pautado a discussão em âmbito nacional e internacional na busca de uma solução para a crise de recursos hídricos que não seja sua disputa por meio de guerras.

O desafio de implementar políticas públicas de gestão democrática da água é um desafio para vários Estados brasileiros, em especial para aqueles com regiões áridas ou semiáridas, pois a degradação deste bem vem ocorrendo em velocidade bem mais rápida do que as medidas efetivamente adotadas para transpor tal crise.

Para encontrar uma solução e alternativas para um problema que reflete o modelo de desenvolvimento baseado no capital, competição, domínio e exploração da natureza, é necessária a participação ampla da sociedade, sobretudo dos povos e comunidades que vivenciam crenças e atitudes que valorizam a água.

Os povos indígenas caracterizam-se pela vida em ambiente rural, estabelecendo uma relação íntima e direta com suas terras e com a natureza nelas presente, da qual se sentem parte integrante e necessitam diretamente para sobreviver. Ao longo de gerações, estabeleceram uma cultura diferenciada com valores pautados no respeito à Mãe Terra.

Por isto, nas diversas leis das águas, estes povos possuem assento nos espaços criados para discussão e gestão dos recursos hídricos. Mas até que ponto a presença dos povos indígenas tem garantido sua efetiva participação na gestão democrática das águas? Quais os fatores que limitam ou favorecem esta participação?

Partindo destas inquietações, a pesquisa teve por objetivo geral analisar a participação indígena nos Comitês de Bacia Hidrográfica do Estado da Bahia, no período de 2006 até o ano de 2009. 
SANDRA C. SMITH GALVÃO - Participação indígena no Comitê de Bacia Hidrográfica...

Para tanto, foram traçados dois objetivos específicos: mensurar o nível de participação dos povos indígenas nos Comitês de Bacia Hidrográfica do Estado da Bahia, bem como identificar os fatores que dificultam ou favorecem esta participação.

A vertente teórico-metodológica adotada é a jurídico-sociológica, a qual se propõe a compreender o Direito como variável dependente da sociedade. Preocupa-se com a faticidade do Direito e com as relações, por vezes contraditórias, que estabelece com os demais campos: sociocultural, político, antropológico e ambiental.

A estratégia metodológica utilizada foi a observação participante, que tem referência empírica e é realizada a partir de procedimentos pautados na troca permanente de internalidades/externalidades, favorecendo a resolução de problemas coletivos, transformações de realidades emergentes e a produção de conhecimento.

A observação participante deu-se através dos seguintes procedimentos: 1) Pesquisa documental; 2) Pesquisa de Campo; 3) Avaliação quanti-qualitativa dos dados levantados.

A pesquisa documental consistiu na seleção e sistematização de dados secundários que sinalizaram o ponto de partida da pesquisa. Nesta primeira fase, foram analisadas a legislação, produção científica, relatórios, atas das reuniões do Comitê, seu Regimento Interno, mapas, fotografias e material de fonte midiática disponível.

A pesquisa de campo compreendeu algumas ações: 1) Participação em reuniões ordinárias e extraordinárias do comitê; 2) Conversas informais com seus membros, principalmente os representantes dos povos indígenas; 3) Elaboração de relatório de campo.

Após a compilação documental e as observações produzidas em campo, os dados obtidos foram avaliados através de indicadores de gestão participativa, quantitativos e qualitativos, perfazendo a última etapa da pesquisa.

Percorrendo este caminho, o trabalho subdivide-se em três partes. Primeiramente, analisou-se o conceito de participação a partir da organização da sociedade civil e do planejamento participativo, bem como sob seu aspecto ético, ou seja, como resultado do conjunto de valores que norteiam pensamentos, palavras e ações na relação com o 
SANDRA C. SMITH GALVÃO - Participação indígena no Comitê de Bacia Hidrográfica...

outro.

Num segundo momento foi feito o estudo da legislação ambiental, em especial a Política Nacional e Estadual de Recursos Hídricos, investigando-se o papel dos Comitês de Bacia Hidrográfica no Sistema de Gestão dos Recursos Hídricos, considerado como um espaço de encontro e troca de saberes.

Por fim, para o estudo de caso do Comitê de Bacia Hidrográfica do Rio Itapicuru - CBHI, foi analisada a participação dos povos indígenas Kaimbé e Kiriri, identificando os fatores que favoreceram ou dificultaram a participação indígena neste comitê, desde sua criação em 2006 até o ano de 2009.

\section{Afinal, o que é participação?}

A Constituição de 1988 estabeleceu que a República Federativa do Brasil constitui-se num Estado Democrático de Direito, tendo a cidadania como um de seus princípios fundamentais.

Assim, o Brasil adotou a democracia, como regime político, que se funda nos princípios da soberania popular e na distribuição equitativa do poder. Logo, a promoção da cidadania, através de um processo contínuo de conquista de direitos, é o objetivo que deve permear a relação entre a sociedade e o Estado.

Assim, o conceito político de participação, como processo de conquista, pressupõe a organização da sociedade civil e o planejamento participativo, tendo como resultado útil a autopromoção e negociação.

Sob a perspectiva da ética, a participação pressupõe uma atitude de abertura ao diálogo e respeito às diferenças no encontro com o outro, capaz de promover e valorizar a diversidade.

\subsection{Participação como conquista}

O significado da palavra participação traz em si a ideia de um processo aberto e dinâmico, por implicar nas relações de troca e poder que se estabelecem entre as partes, em constante mudança, na 
SANDRA C. SMITH GALVÃO - Participação indígena no Comitê de Bacia Hidrográfica...

conquista de direitos.

Este processo de conquista será determinado pelas relações de poder que se estabelecem entre a sociedade civil e o Estado. Vale ressaltar que não há necessariamente a dicotomia entre Estado e Sociedade Civil, a questão é saber a quem o Estado serve e quem o controla:

Para que o Estado cumpra sua função de espaço estratégico de luta democrática, é mister concebê-lo como instância instrumental da sociedade e nunca escamotear sua tendência histórica típica de representar os iguais (...). É certo: o início de processos participativos está na capacidade de organização da sociedade civil, porque só assim adquire vez e voz (DEMO, 1988, p. 34).

A sociedade civil tem o papel de organizar-se, fortalecendo-se através da união de seus diversos segmentos, que devem escolher seus líderes com representatividade legítima, dando visibilidade às demandas sociais, criando Políticas Públicas de Estado, que devem pautar a agenda governamental.

Para que isto aconteça é necessária a identificação comunitária, ou seja, a "criação de símbolos e valores que caracterizam o modo de ser de uma sociedade" (DEMO, 1988, p. 55), através da formação de uma consciência social, que revela as relações de poder de que ela se reveste.

Para a formação da identidade e consciência social, a educação exerce papel fundamental, funcionando como um catalisador da cidadania, alcançando a autopromoção ${ }^{2}$ com vistas à formação do sujeito com direitos e deveres.

Por seu turno, cabe ao Estado, para seu próprio desenvolvimento, ter como modus operandi o planejamento participativo, intermediando e fomentando a negociação ${ }^{3}$ entre os conflitos de interesses dos diversos segmentos sociais com objetivo de construir uma sociedade mais justa e igualitária.

\footnotetext{
${ }^{2}$ Autopromoção é característica de uma política social centrada nos próprios interessados, que passam a autogerir ou pelo menos a cogerir a satisfação de suas necessidades, com vistas a superar a situação assistencialista de carência de ajuda, residualistas e emergenciais (DEMO, 1988).

${ }^{3}$ Negociação significa o tratamento de divergência sobre o pressuposto das oportunidades equalizadas. Ou seja, de igual para igual pelo menos em tese (DEMO, 1988).
} 
Para fomentar a negociação, o Estado deve promover a distribuição igualitária de poder, dando oportunidade para todos. Para isto, deve garantir aos segmentos sociais condições mínimas para o exercício da cidadania ativa, diminuindo as desigualdades que negam os direitos sociais, econômicos e culturais, que caminham juntos com os civis e políticos.

O planejamento participativo no qual deve se pautar o Estado é fruto da organização da sociedade civil, formada pelos seus agentes, ou seja, cada um dos sujeitos dotados de consciência social, a qual se refletirá em seus pensamentos, palavras e ações individualmente.

Para melhor visualizar as etapas do Planejamento Participativo, é trazido o Modelo Sistêmico de Scarabello (2003), que o divide em seis etapas:

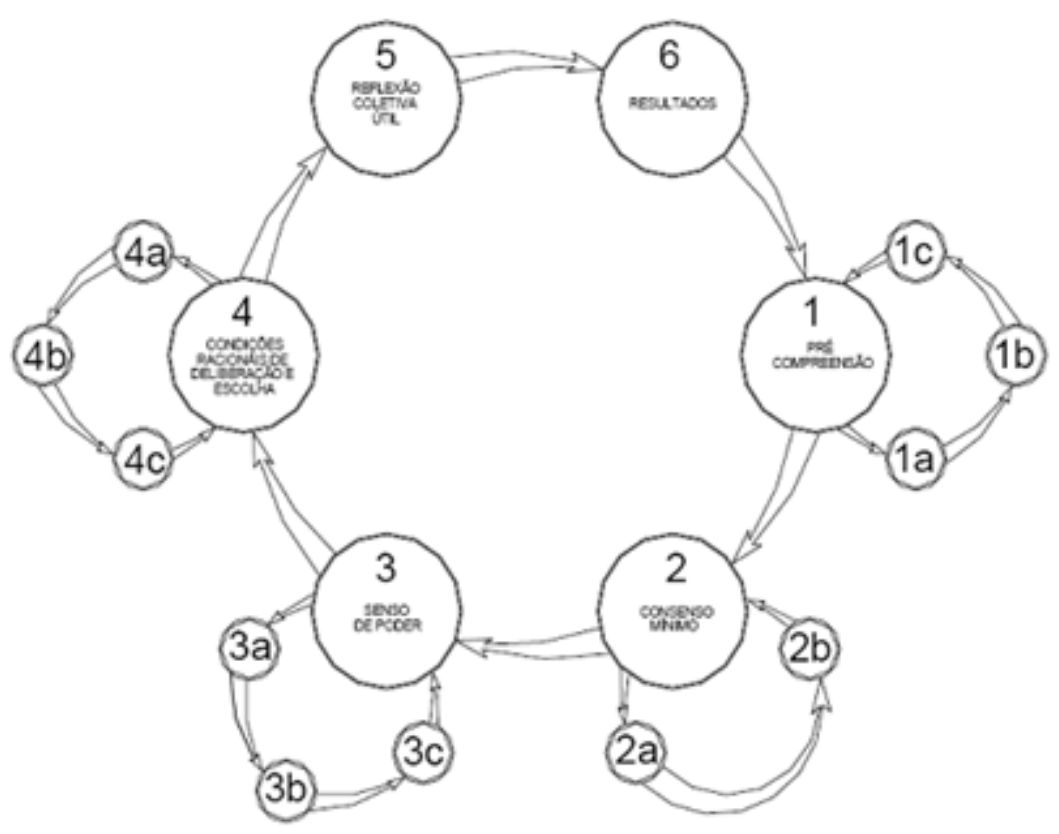

Figura 1. Modelo Sistêmico de Planejamento com Participação Pública (SCARABELLO, 2003. p.55).

Aplicado o modelo ao estudo da pesquisa, a primeira etapa, de Pré Compreensão (1), compreende o conhecimento da natureza da atividade (1a), o conhecimento das características da atividade (1b) e dos objetivos das Políticas Públicas de Recursos Hídricos e dos Comitês de Bacia Hidrográfica (1 c). 
SANDRA C. SMITH GALVÃO - Participação indígena no Comitê de Bacia Hidrográfica...

Daí surge a necessidade de se chegar a um Consenso Mínimo (2), com a identificação e discussão de conceitos específicos (2a) e levantamento das representações sociais (2b).

Para tanto, um senso de poder (3), capacidade e disposição são essenciais, devendo haver por parte dos membros do Comitê credibilidade do processo (3a), senso de comunidade (3b) e equitativa distribuição do poder (3c), o que se verifica com o critério de paridade entre os segmentos.

Também é necessário que estejam presentes as condições racionais de deliberação e escolha (4), através do conhecimento das alternativas (4a), consciência da falibilidade individual (4b) e a abertura para o diálogo (4c) determinarão um bom desempenho da próxima etapa, que é a reflexão coletiva útil.

À proporção em que cada uma dessas etapas se desenvolve, e na medida em que seus elementos fundamentais são observados, ao final ter-se-ão resultados que expressarão o nível de consciência alcançada no final do ciclo, através da autopromoção e negociação, aumentando o nível de cooperação entre os sujeitos.

Semelhante a um sistema vivo, o ciclo se realimenta, expandindo seus arranjos, alargando e fortalecendo sua rede de atuação, dando cor e beleza ao tecido social, através da diversidade cultural de seus membros.

\subsection{Participação como postura ética}

A participação e seus efeitos podem ser analisados a partir do comportamento de cada uma das partes (isolar-se, mostrar-se, fingirse, associar-se e comunicar-se), evidenciado através do processo dialógico que se dá entre elas (a competência ou poder atribuído a cada uma delas).

Observada a relação entre as partes, a participação poderá ser potencializada, tendo como efeito a integração cada vez maior entre as partes, ou enfraquecida, através do isolamento crescente destas.

$\mathrm{Na}$ primeira hipótese, verifica-se a intensificação da comunicação

e associação entre as partes, através de um processo de 
SANDRA C. SMITH GALVÃO - Participação indígena no Comitê de Bacia Hidrográfica...

complementação entre elas, gerando cada vez mais participação.

Já na segunda hipótese, observa-se uma segregação cada vez maior, que interrompe e dificulta a comunicação, mediante uma ação centralizadora, pautada no autoritarismo.

Desse ponto de vista, a participação torna-se uma postura ética face o encontro com o outro, possibilitada pela abertura ao diálogo e potencializada pela diversidade cultural, através da prática de valores como o respeito e tolerância.

Numa sociedade onde as pessoas são livres para expressarem sua singularidade, respeitando os outros, pois a ninguém é dado o direito de causar dor a outrem, a identidade cultural é fortalecida, nascendo daí o poder/dever de participar na construção de uma convivência baseada numa cultura de paz.

\section{Políticas públicas de gestão das águas}

Feitas as devidas considerações sobre o que é participação, cabe agora identificar quais são os espaços de planejamento participativo instituídos nas políticas públicas de gestão de recursos hídricos, e como os sujeitos da sociedade civil organizada deles participam.

Durante muito tempo, acreditou-se na inesgotabilidade dos recursos hídricos. A constatação de tal equívoco, pois apenas $1 \%$ de toda água do planeta se encontra disponível para uso, levou a humanidade a buscar formas de desenvolvimento sustentável visando à conservação deste recurso natural, dotado de elevado valor estratégico e social.

No Brasil, embora a produção hídrica seja abundante, sua distribuição no território é bastante irregular, principalmente se comparada com os assentamentos humanos. A Amazônia, que concentra aproximadamente $80,8 \%$ do potencial hídrico, abriga apenas

$5 \%$ da população. A fartura de água na Amazônia faz contraste com a escassez no semiárido brasileiro, onde se encontram áreas afetadas pelo processo de desertificação.

As políticas públicas podem ser entendidas como o "conjunto de procedimentos formais e informais que expressam relações de poder 
SANDRA C. SMITH GALVÃO - Participação indígena no Comitê de Bacia Hidrográfica...

que se destinam à resolução pacífica dos conflitos quanto a bens públicos" (RUAS, 2009), visando prevenir ou intermediar conflitos pelo uso da água.

Assim, as Políticas Nacional e Estadual de Recursos Hídricos foram criadas com o objetivo de assegurar à atual e às futuras gerações a necessária disponibilidade de água, em padrões de qualidade adequados aos respectivos usos, e sua utilização racional e integrada.

\subsection{A política nacional de recursos hídricos}

No contexto de milagre econômico, em 1934, o Decreto-lei 24.643/1934 instituiu o Código das Águas com a preocupação de dar uma resposta ao setor industrial, que definiu como prioridade o uso das águas para o aproveitamento dos potenciais hidráulicos, formando a matriz energética do Brasil.

Com a promulgação da Carta Constitucional de 1988, o conceito de meio ambiente foi ampliado, exigindo uma nova disciplina jurídica sobre as águas, agora centrada na importância ambiental dos recursos hídricos e determinando sua dominialidade por parte da União e Estados.

Assim, em 8 de janeiro de 1997 foi aprovada a lei 9.433/97, que estabelece a Política Nacional de Recursos Hídricos - PNRH, criando o Sistema Nacional de Gerenciamento de Recursos Hídricos - SINGREH, bem como seu respectivo Sistema de Informações.

Entre os princípios que norteiam a PNRH, destaca-se a eleição da bacia hidrográfica como unidade territorial para a gestão das águas, que deve ser descentralizada e contar com a participação do Poder Público, usuários e das comunidades (art. $1^{\circ}$, V e VI da lei 9.433/97).

A gestão é descentralizada, pois as decisões devem partir dos diversos órgãos que compõem o sistema, funcionando de forma articulada e participativa, pois deve garantir que os diversos setores sociais façam parte de um planejamento participativo capaz de estabelecer e implementar as ações em cada bacia hidrográfica.

A bacia hidrográfica é 
SANDRA C. SMITH GALVÃO - Participação indígena no Comitê de Bacia Hidrográfica...

o conjunto de terras drenadas por um corpo de água principal e seus afluentes e representa a unidade mais apropriada para o estudo qualitativo e quantitativo do recurso água e dos fluxos dos sedimentos e nutrientes (PIRES, SANTOS e DEL PRETTE, 2002, p. 4).

Já os Comitês de Bacias Hidrográficas são órgãos de base do sistema de gestão de recursos, tendo como competência promover o diálogo, arbitrar conflitos, aprovar e acompanhar a execução do plano de bacia hidrográfica, propor normas para uso das águas, além de promover a aplicação do instrumento de cobrança no território da sua bacia.

\subsection{A lei $11.612 / 09$ e o papel dos Comitês de Bacia Hidrográfica}

Seguindo as regras gerais da Política Nacional de Recursos Hídricos, estabelecidas pela União, conforme competência constitucional prevista no art. 21, XIX, o Estado da Bahia teve sua primeira Política das Águas aprovada mediante a Lei n. 6.855/95. Posteriormente veio a Lei 10.432/06, atualmente vigendo a Lei Estadual n. 11.612, de 8 de outubro de 2009.

O Sistema Estadual de Recursos Hídricos tem como órgão consultivo e deliberativo o Conselho Estadual de Recursos Hídricos CONERH, como órgão central a Secretaria Estadual de Meio Ambiente SEMA, como órgão executor o Instituto de Meio Ambiente e Recursos Hídricos - INEMA e os Comitês de Bacias Hidrográficas como órgãos responsáveis pela gestão descentralizada e participativa (BAHIA, 2009).

Os Comitês de Bacias Hidrográficas são órgãos colegiados de caráter consultivo, normativo e deliberativo, vinculados ao CONERH, com área de atuação na unidade de gestão hidrográfica, ou seja, na bacia hidrográfica correspondente.

Com a existência dos Comitês, as decisões relacionadas ao setor de recursos hídricos passam a ser descentralizadas do poder público estadual, municipal e federal, também fazendo parte deste processo os representantes dos usuários e das organizações civis de recursos hídricos com atuação comprovada na bacia. 
SANDRA C. SMITH GALVÃO - Participação indígena no Comitê de Bacia Hidrográfica...

O Comitê de Bacia Hidrográfica é formado por uma Diretoria (presidente, vice-presidente e secretário), Secretaria Executiva, Câmaras Técnicas e pela Plenária, conjunto de seus membros convocados para reuniões ordinárias e extraordinárias do comitê.

A Secretaria Executiva do Comitê de Bacia Hidrográfica deve ser exercida por uma Agência de Bacia, ficando suas competências a cargo do órgão executor da política estadual de recursos hídricos, enquanto não for criada.

Apesar de sua grande extensão territorial, até o ano de 2009, o Estado da Bahia só contava com seis comitês de bacia hidrográfica em funcionamento, ou seja, criados e com seus membros empossados: Itapicuru, Litoral Norte, Salitre, Paraguaçu, Verde Jacaré e Leste4. Número baixo, se comparado a outros Estados com menor extensão territorial e com maior número de comitês.

Uma das atividades primordiais do comitê é o acompanhamento da elaboração do plano de bacia hidrográfica onde está inserido, através do qual será feito o diagnóstico e prognóstico, mapeando-se as potencialidades e dificuldades da realidade da bacia, e daí traçando-se metas a serem atingidas.

É a partir do plano de bacia que poderão ser estabelecidos critérios, restrições de uso e proposto ao CONERH o enquadramento das águas da bacia hidrográfica pelo comitê, criando-se normas para se alcançar a realidade desejada.

Assim, o planejamento participativo é fundamental para o comitê, com encontros onde todos os representantes dos diversos segmentos sociais possam participar ativamente na elaboração de seu plano de bacia, acompanhar sua execução e avaliar os resultados.

Quanto à participação dos índios, conforme o art. 55, $\S 3^{\circ}$ da Lei Estadual n. 11.612/2009, nos comitês de bacia hidrográfica cujos territórios abranjam terras indígenas devem ser incluídos representantes das comunidades indígenas residentes ou com interesse na bacia e da Fundação Nacional do Índio - FUNAI.

Como está prevista a paridade entre os segmentos poder público,

\footnotetext{
${ }^{4}$ Quando foi encerrada a pesquisa, em 2009, se encontravam em processo adiantado de criação mais quatro novos comitês: 1)Rio de Contas; 2) Corrente; 3) Grande e 4) Entorno do Lago de Sobradinho. Nos dias atuais, além dos oito já citados somam-se mais quatro: 1) Recôncavo Sul; 2) Peruípe, Itanhém e Jucuruçu; 3) Frades, Bunharém e Santo Antônio e 4) Paramirim e Santo Onofre.
} 
SANDRA C. SMITH GALVÃO - Participação indígena no Comitê de Bacia Hidrográfica...

usuários e organismos da sociedade civil, a questão é saber se os povos indígenas formariam um segmento à parte ou se disputariam suas vagas dentro deste último setor.

Este questionamento, bem como qual é o número de vagas destinadas aos povos indígenas, é respondido com a análise do Regimento Interno de cada comitê, com competência para tratar sobre o assunto.

Sendo o Comitê de Bacia Hidrográfica do Rio Itapicuru - CBHI o único entre os seis já criados com representação indígena, desde 2006 até o ano de fechamento desta pesquisa, em 2009, no próximo capítulo far-se-á um estudo de caso sobre o mesmo, quanto a esta participação.

\section{Participação indígena no Comitê de Bacia Hidrográfica do Rio Itapicuru no estado da Bahia}

Para avaliar a participação indígena nos Comitês de Bacias Hidrográficas no Estado da Bahia, em especial a CBH do Rio Itapicuru, foram estabelecidos indicadores quantitativos e qualitativos.

Antes da análise destes indicadores, foram feitas algumas considerações sobre o território da Bacia Hidrográfica do Rio Itapicuru, como ocupação, disponibilidade hídrica e presença indígena.

\subsection{A bacia hidrográfica do Rio Itapicuru e seu comitê}

De acordo com o Plano Estadual de Recursos Hídricos - PERH-BA, de 2004, a Bacia Hidrográfica do Rio Itapicuru corresponde à XII Região de Planejamento e Gestão das Águas - RPGA, e localiza-se na região nordeste do Estado.

O CBHI possui uma superfície de $37.345 \mathrm{~km}^{2}$ (trinta e sete mil, trezentos e quarenta e cinco quilômetros quadrados), onde residem cerca de 989.047 pessoas (novecentos e oitenta e nove mil e quarenta e sete), conforme dados do censo IBGE do ano de 2000.

Dentro do $\mathrm{CBHI}$, os povos indígenas atingem uma população aproximada de 2.659 habitantes, distribuídos em dezenove 
SANDRA C. SMITH GALVÃO - Participação indígena no Comitê de Bacia Hidrográfica...

comunidades. Eles ocupam cerca de 20.320ha, distribuídos entre os povos Kiriri, que ocupam terras dos municípios de Quijingue e Banzaê, com uma e dez comunidades, respectivamente; e os Kaimbés, com terra denominada de Massacará, organizados em oito comunidades distintas concentradas no município de Euclides da Cunha (SEl, 2006).

Quanto ao Índice de Desenvolvimento Social - IDS, para o qual são analisadas a expectativa de vida, a educação e a renda, dos cem municípios de menores IDH do Estado em 2000, trinta e cinco encontram-se nessa área. Todos os municípios do $\mathrm{CBHI}$ se enquadram em índices médios na faixa entre 0,500 e 0,650; no entanto, na avaliação de 1991, o município de Quijingue, onde se localiza parte do território Kiriri, figurava como o de pior IDH do Estado, com índice 0,377, vindo a melhorar sua posição apenas em 2000 (SEl, 2006).

Registre-se que no território da Bacia do Rio Itapicuru já tinha sido reservada uma área para o Povo Tuxá, que, em razão da construção de uma barragem em seu território original, localizado no Município de Ibotirama, seria deslocado para lá, segundo demonstra o mapa.

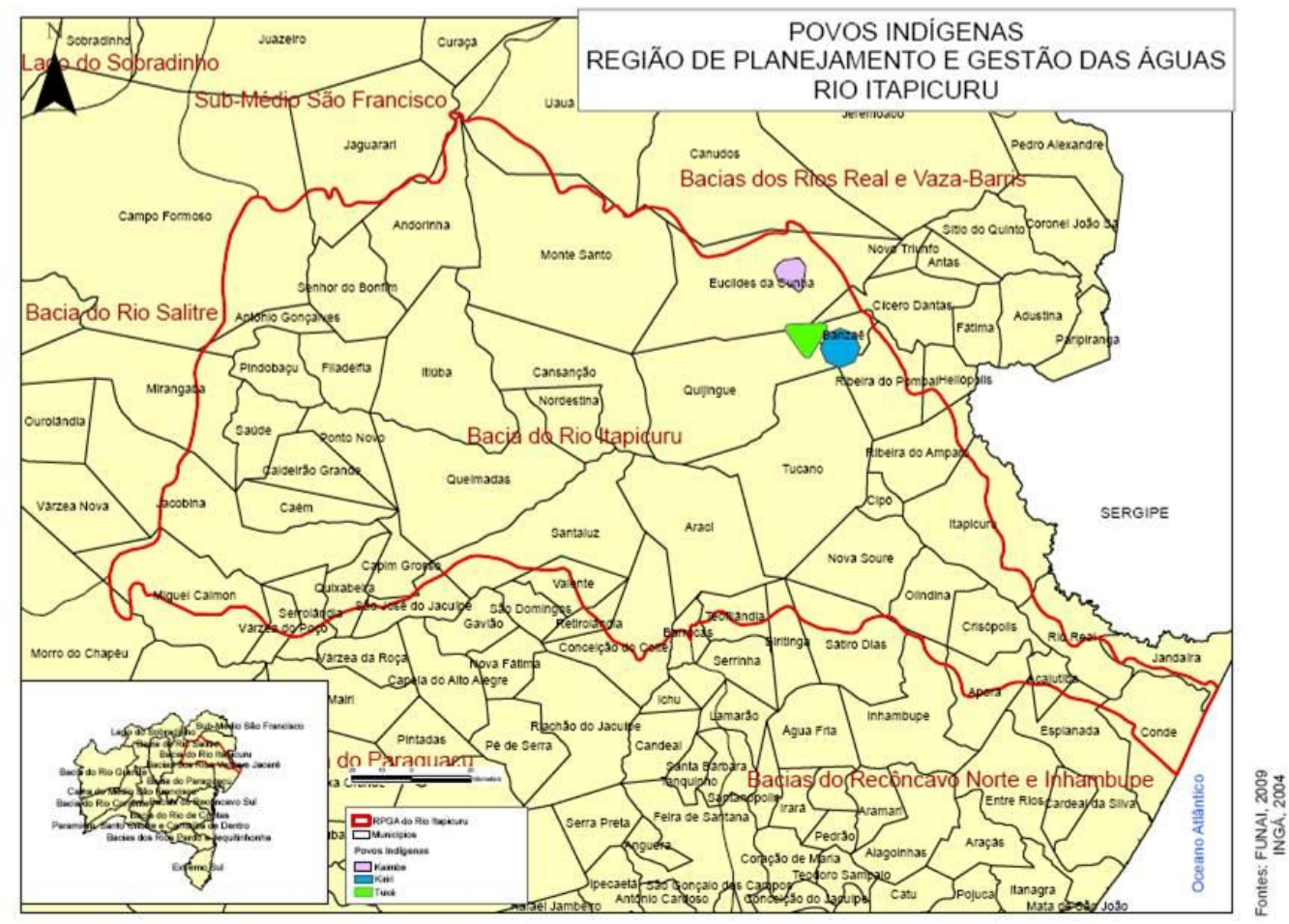

Figura 2. Povos Indígenas e RPGA (GALVÃO, 2010). 
SANDRA C. SMITH GALVÃO - Participação indígena no Comitê de Bacia Hidrográfica...

O clima semiárido predomina em $81 \%$ da área, ocupando a parte central da RPGA, com chuvas anuais inferiores a $700 \mathrm{~mm}$. A maioria dos cursos d'água, principalmente no trecho médio da RPGA, apresentam vazões de estiagem praticamente nulas. Devido à escassez hídrica da região, o Departamento Nacional de Obras contra a Seca - DNOCS implantou uma série de intervenções hídricas, a exemplo dos reservatórios de Ponto Novo, Barroca do Faleiro e Pedras Altas.

Com a competência de arbitrar os frequentes conflitos pelo uso da água dentro da bacia, o Comitê de Bacia Hidrográfica do Rio Itapicuru, teve sua proposta de instalação aprovada pela Resolução CONERH $n^{\circ} 9$, de 14 de fevereiro de 2006. Em 22 de março de 2006, foi efetivamente criado, com a publicação do Decreto n ${ }^{\circ}$ 9.937/2006.

\subsection{Dos indicadores quantitativos}

Após a compilação dos dados documentais e das observações produzidas em campo, através da realização de conversas informais e elaboração de relatório de campo, estes dados foram avaliados através de indicadores de gestão participativa.

Os indicadores quantitativos utilizados foram: 1) Número de vagas reservadas e preenchidas para os povos indígenas; 2) Quantidade de presenças indígenas nas reuniões; 3 ) Número de intervenções indígenas registradas em ata; 4) Número de demandas levantadas pelos indígenas e atendidas pelo $\mathrm{CBHI}$.

\subsubsection{Número de vagas}

Da análise do Regimento Interno do $\mathrm{CBHI}$, observa-se que, quando de sua instalação, era composto por 37 (trinta e sete) vagas, com duas reservadas para os povos indígenas, sendo dois titulares e dois suplentes.

No entanto, devido à dificuldade de se atingir o quórum mínimo nas reuniões, o regimento interno foi alterado na reunião de 29 de 
SANDRA C. SMITH GALVÃO - Participação indígena no Comitê de Bacia Hidrográfica...

setembro de 2009, diminuindo para 27 (vinte e sete) o número de assentos com representações estabelecidas de forma tripartite e paritária, com representações dos segmentos Poder Público, Usuários e Sociedade Civil Organizada.

Do total das 27 vagas, foram destinados 03 (três) assentos para representantes dos povos indígenas residentes ou com interesse na Bacia Hidrográfica (art. $5^{\circ}$, IV).

Além destas três vagas, dentro do segmento da sociedade civil organizada foram reservadas três vagas para os Povos e Comunidades Tradicionais 5 , com atuação comprovada na área desta bacia hidrográfica, conforme art. $5^{\circ}$, III, b do seu Regimento Interno.

Assim, além de poder disputar as vagas dos Povos e Comunidades Tradicionais dentro do segmento Sociedade Civil Organizada, também poderão apontar mais três representações indígenas em segmento próprio, à parte.

Esta é uma interpretação da norma, podendo também ser defendido que a partir do momento em que há um segmento específico, os povos indígenas não podem concorrer às vagas dos Povos e Comunidades Tradicionais. O entendimento que prevalecerá dependerá das relações de poder que se estabelecerão no $\mathrm{CBHI}$ e do reconhecimento do grupo da importância da maior representação indígena.

\subsubsection{Número de presenças}

Desde sua criação, em 2006, foi convocado um total de 12 (doze) Reuniões Plenárias do CBHI, sendo que uma delas, do dia 29/05/2008, não foi realizada por falta de quórum de instalação.

Através da análise das listas de presença das reuniões plenárias do $\mathrm{CBHI}$, do total de 11 reuniões ocorridas entre os dias 31 de junho de 2007 e 9 de novembro de 2009, os representantes indígenas se fizeram

\footnotetext{
${ }^{5}$ Regimento Interno do CBHI, art. $6^{\circ}$. Entende-se por Povos e Comunidades Tradicionais os grupos culturalmente diferenciados e que se reconhecem como tais, que possuem formas próprias de organização social, que ocupam e usam territórios e recursos naturais como condição para sua reprodução cultural, social, religiosa, ancestral e econômica, utilizando conhecimentos, inovações e práticas gerados e transmitidos pela tradição.
}

Espaço Ameríndio, Porto Alegre, v. 7, n. 1, p. 146-169, jan./jun. 2013. 
SANDRA C. SMITH GALVÃO - Participação indígena no Comitê de Bacia Hidrográfica...

presente em 9 (nove).

\begin{tabular}{|c|c|c|c|}
\hline Data & Local & $\begin{array}{l}\text { Presença } \\
\text { Indígena }\end{array}$ & $\begin{array}{l}\text { Registro de falas } \\
\text { Indígena }\end{array}$ \\
\hline $31 / 05 / 2007$ & Senhor do Bonfim & Sim & Não \\
\hline 17/07/2007 & Ribeira do Pombal & Sim & Não \\
\hline 17 e 18/09/07 & Conde & Sim & Não \\
\hline 15/01/2008 & Jacobina & Sim & Sim \\
\hline 26 e 27/02/08 & Tucano/Jorro & Sim & Não \\
\hline 29/05/2008 & Queimadas & - & - \\
\hline $17 / 03 / 2009$ & Euclides da Cunha & Sim & Sim \\
\hline $17 / 04 / 2009$ & Pindobaçu & Não & Não \\
\hline $16 / 07 / 2009$ & Ponto Novo & Sim & Sim \\
\hline $3 / 09 / 2009$ & Senhor do Bonfim & Não & Não \\
\hline 29/09/2009 & Itiúba & Sim & Sim \\
\hline 09/11/2009 & Banzaê & Sim & Sim \\
\hline
\end{tabular}

Figura 3 - Tabela/Lista de Reuniões e Participação Indígena (Elaboração própria).

Para os quatro anos de existência analisados, a média de três reuniões anuais é um número razoável, embora se possa notar que no primeiro ano de formação (2006) não há registro de reuniões, e que no ano de 2009 houve uma concentração, com a realização de seis reuniões.

Esta variação tem a ver com a história do Comitê, bem como com as mudanças de governo no Estado da Bahia durante o período, que serão analisadas mais detalhadamente no item que trata dos indicadores qualitativos.

Os dados levantados também demonstram que, nas nove reuniões em que representantes indígenas fizeram-se presentes, apenas em quatro delas há registro de falas indígenas em atas. Qual a razão e o 
SANDRA C. SMITH GALVÃO - Participação indígena no Comitê de Bacia Hidrográfica...

que se revela neste silêncio?

\subsubsection{Número de demandas levantadas e atendidas}

Do total de quatro registros das falas indígenas, em três deles foram trazidas demandas dos povos indígenas para o comitê, sendo que na fala da reunião do dia 16/7/2009 foi feito um registro de afirmação da identidade dos povos indígenas.

Das demandas apresentadas, apenas uma foi satisfatoriamente atendida, por meio da ampliação do número de vagas destinadas aos povos indígenas, e as demais não foram atendidas ou apenas atendidas parcialmente.

\subsection{Indicadores qualitativos}

Os indicadores qualitativos vão além da mera quantificação dos dados, buscando o significado neles embutidos, a serem postos à luz através da sua interpretação, que considera o contexto e a história no qual se originam.

O olhar voltado para os dados quantitativos, a fim de identificar os fatores que dificultam ou facilitam a participação indígena no CBHI, terá como fundamento o conceito de participação trazido na primeira parte da pesquisa.

Desta forma, serão discutidos os pressupostos de organização da sociedade civil, através da identidade comunitária e representatividade da liderança, e o planejamento participativo por meio do acesso à informação e formação dos membros.

Os indicadores qualitativos estabelecidos foram: 1) identidade comunitária dos povos indígenas; 2) representatividade das lideranças indígenas; 3) o acesso às informações pertinentes ao comitê; 4) condição socioeconômica dos povos indígenas.

A avaliação qualitativa teve como base as atas das reuniões e Regimento Interno do CBHI, bem como os relatórios de campo, fruto da participação direta da pesquisadora nas reuniões do comitê. Utilizou-se 
SANDRA C. SMITH GALVÃO - Participação indígena no Comitê de Bacia Hidrográfica...

a análise do discurso do sujeito coletivo (LEFRÈVE, 2003) para desnudar as relações de poder nos registros das falas e silêncios dos representantes indígenas.

\subsubsection{Identidade comunitária dos povos indígenas}

O índio identifica-se com sua comunidade por uma série de traços característicos como língua, mitos, valores, modos próprios de ser e interagir com a natureza e assim por diante. Com base em tais traços a comunidade se materializa e se organiza assumindo a identidade de grupo.

Essa identidade comunitária se faz fortemente presente entre os povos indígenas, "os parentes", através da sua afirmação cultural. O índice de escolaridade é baixo nas comunidades indígenas, poucos tendo acesso à formação superior, o que demonstra que cultura é algo que se aprende não apenas na educação formal.

Um bom exemplo disto é revelado na ata da reunião do dia 17/07/2007, em Ribeira do Pombal, onde, apesar de não haver 0 registro de fala dos indígenas, foram eles responsáveis pela parte cultural do encontro, sendo feita a apresentação do Toré6, que é uma forma de linguagem corporal.

Na reunião do dia 16/07/2009, também há uma afirmação da identidade quando a representante indígena pontua que, "para envolver o nome das comunidades tradicionais no documento, os representantes das comunidades deveriam ser consultados", não aceitando a condição de massa de manobra.

Por outro lado, o silêncio indígena na maioria das reuniões que estiveram presentes revela uma falta de identidade dos indígenas com o próprio grupo do comitê, a linguagem formal de seus membros e sua

\footnotetext{
${ }^{6}$ O Toré é um ritual praticado pela quase totalidade dos povos indígenas do Nordeste. É dançado ao ar livre por homens e mulheres que, aos pares, formam um grande círculo que gira em torno do centro. Cada par, ao acompanhar os movimentos, gira em torno de si próprio, pisando fortemente o solo, marcando o ritmo da dança, acompanhado por instrumentos como maracás, gaitas e pelo coro de vozes dos dançarinos. Esse ritual é um elemento essencial na organização social e política dos povos indígenas do Nordeste, e constitui seu principal elemento de afirmação de uma identidade indígena, tanto internamente, como nas relações com a população local e com os órgãos oficiais (LAIGNEAU, 2006).
} 
SANDRA C. SMITH GALVÃO - Participação indígena no Comitê de Bacia Hidrográfica...

própria dinâmica de funcionamento, pautada em normas muitas vezes desconhecidas ou das quais não participaram da construção, como demonstrarão os itens seguintes.

\subsubsection{Representatividade da liderança}

Quanto à representatividade, tudo indica que a formação do comitê se deu de uma forma autoritária, sendo imposta pelo Estado, sem ter sido encontrado nenhum documento que relatasse algum tipo de mobilização prévia.

A que tudo indica, inicialmente as vagas para os povos indígenas foram criadas em função da regra geral estabelecida na PNRH, que deveria ser observada também na política estadual; portanto, mais pautada no simbolismo da presença indígena, vinculada ao cuidado com a Natureza.

Assim, inicialmente os representantes indígenas não foram indicados pelo próprio povo:

Um tempo depois, em reunião na SRH [Superintendência de Recursos Hídricos], a direção do Comitê informou que a FUNAI [Fundação Nacional do Índio] havia indicado um Kaimbé pra fazer parte. A gente ficou sabendo da participação de uma pessoa no comitê, mas a maioria não sabia o que é (UCSal, 2008 - Depoimento Kaimbé, Relatório de campo, abril de 2007).

Só posteriormente os povos indígenas foram verdadeiramente se apropriando do seu espaço no $\mathrm{CBHI}$, indicando suas lideranças escolhidas em reuniões com as comunidades, inclusive tendo sido atendidos quanto à demanda de criação de mais uma vaga para o povo indígena Tuxá.

\subsubsection{Acesso à informação}

Outra demanda registrada foi a dificuldade de acesso à informação, seja pela linguagem rebuscada, seja pela diferença de 
SANDRA C. SMITH GALVÃO - Participação indígena no Comitê de Bacia Hidrográfica...

cosmovisão de quem escreve e do índio que as lê, elaboradas sem a participação deste.

Os indígenas humildemente reconhecem a dificuldade como sendo deles, e afirmam o interesse em aprender e o compromisso em compartilhar com sua comunidade o que fora aprendido e deliberado pelo comitê:

O setor indígena relatou que em suas discussões chegaram a conclusão que os mesmos têm falta de conhecimento das Leis e sentem a necessidade de passar as informações para suas comunidades (Ata da reunião do CBHI, Jacobina, 15/01/08).

Após o registro desta fala, e durante os quatro anos de criação do CBHI, só foi realizada uma capacitação com seus membros, no dia 30 de maio de 2008, com duração de um dia apenas.

A invisibilidade dos povos indígenas no momento de criação e escolha dos primeiros representantes indígenas se repetiu na elaboração do material fornecido na capacitação:

A ocupação do semi-árido data dos primeiros séculos da colonização, quando bandeirantes adentraram o país em busca de ouro (Projeto Marca d'Água, 2003, p.58).

Assim, a demanda não foi atendida, sendo reivindicada uma formação específica para os povos indígenas, em documento entregue à Diretoria na reunião do dia 17/03/2009, ainda sendo levantados os seguintes pontos:

1. Quando chega a comunicação; 2. Do lugar que é escolhido para realizar; 3 . Aumentar o número de vagas aos povos e comunidades tradicionais; 4 . Transparência das contas do Comitê; Plano deve ser encaminhado; 6. Secretaria Executiva autônoma desvinculado do órgão executor INGÁ e sim articulado ao próprio; 7. Alteração da legislação para viabilizar a autonomia do comitê com a criação da Secretaria Executiva; 8. Formação específica para o povo indígena não foi feita ${ }^{7}$ (Ata CBHI, reunião de 17/03/2009).

\footnotetext{
${ }^{7}$ Uma alternativa de formação específica pode-se espelhar nos moldes dos "Encontros pelas Águas" realizados nos anos de 2007 e 2009, visando a promoção da justiça socioambiental, com a inclusão de povos e comunidades tradicionais, sendo necessária a articulação entre a políticas públicas das águas e educação ambiental.
}

Espaço Ameríndio, Porto Alegre, v. 7, n. 1, p. 146-169, jan./jun. 2013. 
O pouco acesso à tecnologia dificulta a comunicação, agravando o fato dos territórios indígenas ficarem distantes dos centros urbanos, sem cobertura de internet e telefonia celular. As correspondências muitas vezes também chegam com algum atraso devido às más condições das vias de acesso.

Inclusive este foi o motivo da ausência dos indígenas a uma das reuniões do comitê: sendo enviada carta convocatória com poucos dias de antecedência, não chegou a tempo, inviabilizando a participação indígena.

Além disto, na maioria das vezes, as convocações encaminhadas por AR (Aviso de Recebimento) não são acompanhadas dos documentos a serem discutidos na reunião, que requerem uma leitura prévia e estudo mais apurado.

\subsubsection{Condição socioeconômica dos povos indígenas}

Outro ponto que se destaca é a dificuldade financeira dos povos indígenas para viabilizar sua participação nas reuniões do CBHI, pois sua economia é pautada na troca da produção agrícola de subsistência, sendo baixo o IDS nas comunidades indígenas, conforme anteriormente relatado.

O custeio das despesas com deslocamento, alimentação e estada dos representantes das organizações civis de recursos hídricos para participarem das reuniões dos comitês está legalmente assegurado. Estes custos são ressarcidos pela SEMA a posteriori, sendo um dos motivos da ausência indígena às plenárias quando não têm dinheiro disponível.

Além disto, na sua maioria, os representantes dos povos indígenas são trabalhadores rurais, ou artesãos, e quando os mesmos se afastam da aldeia onde vivem para participar das atividades do comitê, eles perdem seus dias de trabalho, por vezes imprescindíveis em determinada época para produção agrícola. 
SANDRA C. SMITH GALVÃO - Participação indígena no Comitê de Bacia Hidrográfica...

\section{Conclusão}

A água é um bem essencial para vida e de valor estratégico para o desenvolvimento econômico e cultural. A crise política, social e ambiental, revela-se também numa crise ética, que exige novas atitudes e valores do ser humano.

Políticas públicas pautadas na gestão descentralizada e participativa estão sendo adotadas, com o objetivo de superar tal crise. Neste contexto, a participação adquire um conceito amplo que envolve a organização da sociedade civil e o planejamento estratégico, bem como a absorção deste conceito em sua perspectiva ética.

Seja pelo simbolismo, seja pela cultura pautada no cuidado e estreita interação com a Natureza, a participação indígena tem recebido papel de destaque nas políticas de gestão dos recursos hídricos.

Apesar da abundância de água no território pátrio, sua má distribuição e a perda acelerada de sua qualidade fizeram com que o Brasil aprovasse sua Política Nacional de Recursos Hídricos, criando seu Sistema de Gestão e de Informação dos Recursos Hídricos, pautado na descentralização e participação social.

O Estado da Bahia possui parte considerável de seu território onde predomina o clima semiárido, sendo um desafio garantir a toda sua população o acesso à água de qualidade em quantidades razoáveis, sem comprometimento das futuras gerações.

Para enfrentar este desafio, a lei baiana das águas, tem no Comitê de Bacia Hidrográfica o espaço de encontro entre poder público, sociedade civil organizada e usuários, com a atribuição de acompanhar a elaboração, aprovação e a execução dos planos de bacia.

Os povos indígenas, bem como a FUNAI, possuem legalmente assento nos comitês de bacias hidrográficas onde residem ou naqueles nos quais tenham interesse. No entanto, é necessário verificar a forma como esta participação de fato acontece.

Desta forma, a pesquisa, através da observação participante, estudo de caso e análise de discurso do sujeito coletivo, mensurou o nível de participação indígena no Comitê de Bacia Hidrográfica do Rio Itapicuru, identificando os fatores que a dificultam ou favorecem, no período de 2006 a 2009. 
SANDRA C. SMITH GALVÃO - Participação indígena no Comitê de Bacia Hidrográfica...

Para tanto, foram levantados dados, com base nos indicadores qualitativos e quantitativos, chagando-se a algumas conclusões que servem de reflexão para outros comitês.

A delimitação de grandes áreas de abrangência de uma única bacia hidrográfica torna sua gestão custosa e difícil para o comitê.

É necessária a formação continuada e específica para os povos indígenas, a fim de diminuir as barreiras encontradas para sua efetiva participação na gestão das águas.

Verificou-se que, embora a forte identidade comunitária dos indígenas tenha papel preponderante na organização e formação de sua consciência social, a negação de seus direitos sociais, econômicos e culturais implica negativamente no exercício de seus direitos civis e políticos.

Por meio do planejamento participativo no âmbito do Comitê de Bacia Hidrográfica, e da articulação entre políticas públicas, o Estado da Bahia juntamente com a sociedade civil organizada tem o desafio de tornar a gestão das águas cada vez mais democrática.

Para tanto, é importante lembrar que as mudanças dependem de uma nova visão e postura ética no encontro com o outro, percebendo na diversidade cultural a possibilidade enriquecedora de aprendizado mútuo.

Conclui-se a pesquisa verificando-se que a participação além de um imperativo legal, trata-se também de escolha pela ética ambiental, capaz de determinar atitudes pautadas no respeito, tolerância e cuidado, valores imprescindíveis para superação da crise ambiental, social e política que desafiam a humanidade.

\section{Referências bibliográficas}

BAHIA. Lei n. 11.612, de 08 de outubro de 2009. Dispõe sobre a Política Estadual de Recursos Hídricos, cria o Sistema Estadual de Gerenciamento de Recursos Hídricos e dá outras providências. Diário Oficial do Estado. Salvador, 09 de outubro de 2009.

DEMO, Pedro. Participação é conquista. São Paulo: Cortez: Autores Associados, 1988. 
SANDRA C. SMITH GALVÃO - Participação indígena no Comitê de Bacia Hidrográfica...

ENCONTRO PELAS ÁGUAS. Cartas pelas Águas: cartas coletivas construídas pelas comunidades tradicionais da Bahia durante os encontros pelas águas. Salvador: SRH, 2007.

LAIGNEAU, Patrick. "Vamos lutar da forma que nós sabemos": estudo etnográfico sobre a participação de representantes indígenas nos comitês de bacias hidrográficas no Brasil - Os estudos do Comitê do Itajaí e do Comitê São Francisco. 2006. 127 f. Dissertação (Mestrado em Antropologia Social) - Universidade Federal do Rio Grande do Sul, [2006].

LEFRÈVE, Fernando; LEVRÈVE, Ana Maria Cavalcanti. O discurso do sujeito coletivo: um novo enfoque em pesquisa qualitativa (desdobramentos). Caxias do Sul: EDUCS, 2003.

PIRES, José Salatiel Rodrigues Pires; SANTOS, José Eduardo dos Santos; DEL PRETTE, Marcos Estevan. A utilização do Conceito de Bacia Hidrográfica para a conservação de Recursos Naturais. In: SCHIAVETTI, Alexandre; CAMARGO, Antonio (Org.). Conceitos de Bacias Hidrográficas: teorias e aplicações. Ilhéus: Editora UESC, 2002.

PROJETO MARCA D’ÁGUA: seguindo as mudanças na gestão das bacias hidrográficas do Brasil. In: FRANK, Beate (Org.). Comitês de bacia sob o olhar de seus membros. Blumenau: FURB, 2008. p. 54.

RUA, Maria das Graças. Políticas públicas. Florianópolis/Brasília: Departamento de Ciências da Administração-UFSC/ CAPES/ UAB, 2009. Disponível em: http://portal.virtual.ufpb.br/biblioteca-virtual/files/pub_1291087408.pdf . Acesso em: 29 jun. 2013.

SCARABELLO, Sinésio Filho. Além dos Conflitos: a participação pública na construção do cenário de futuro - Estudo de Caso - Áreas da Serra do Jarpi - Jundiaí/SP. 2003. 161 f. Dissertação (Mestrado em Engenharia Civil) -UNICAMP, [2003].

SEI - SUPERINTENDÊNCIA DE ESTUDOS ECONÔMICOS E SOCIAIS DA BAHIA. Uso atual das terras: Bacias dos Rios Itapicuru, Vaza-Barris e Real. Salvador: SEI, 2006. (Série Estudos e Pesquisas, 74).

UCSAL, EMBRAPA. Relatório Técnico da Pesquisa Diagnóstica e Prognóstica para Gestão do Uso e Conservação da Água e Sustentabilidade Ecossociocultural no Território Kaimbé: um Diálogo entre Povo Indígena, Universidade e Estado. Salvador: UCSal/Embrapa, 2008.

Espaço Ameríndio, Porto Alegre, v. 7, n. 1, p. 146-169, jan./jun. 2013. 